\title{
Local anaesthesia for venous cannulation and arterial blood gas sampling: are doctors using it?
}

\author{
Daniel M Sado BM BSc ${ }^{1}$ Charles D Deakin MD FRCA ${ }^{2}$
}

$J$ R Soc Med 2005;98:158-160

\section{SUMMARY}

The pain of venous cannulation and arterial puncture can be greatly lessened by local anaesthesia. We sought information about the use of local anaesthesia for these procedures by doctors working in medicine, surgery and anaesthetics. A questionnaire was hand-delivered to 178 doctors in eight hospitals, all of whom responded.

For insertion of large-bore cannulae, local anaesthesia was used by all the anaesthetists but less than half the medical and surgical doctors. For arterial blood sampling it was used by $60 \%$ of anaesthetists and $2 \%$ of ward doctors.

Previous recommendations to use local anaesthesia seem to have been ignored, and in many instances these procedures are more painful than necessary.

\section{INTRODUCTION}

Peripheral venous (IV) cannulation and arterial blood gas (ABG) sampling are two of the most common invasive procedures conducted in medicine. Both can be very painful, and numerous studies have shown that much of the pain can be avoided by use of local anaesthesia. ${ }^{1-7}$ In an emergency there may be no time, but in many instances it is feasible to wait for local anaesthesia to take effect. The agent will usually be given by needle injection. Other, less efficacious, methods are iontophoresis, ethyl chloride spray and carbon-dioxide-powered needleless injection. Local anaesthetic cream can be effective but is expensive and takes as much as an hour to work. ${ }^{8}$

In all the ABG studies the local anaesthetic agent has been given as a subcutaneous bolus, since the radial artery is usually deep under the skin. ${ }^{2,5,6}$ Most of the IV cannulation studies have likewise used subcutaneous injection, though success rates with intradermal injection appear similar. ${ }^{1,3,4,7}$ Without exception, all the research in this area has led to the conclusion that local anaesthesia should be used for routine ABG sampling and IV cannula insertion; however, three surveys of practice during the mid-1990s indicated that ward doctors were much less likely than anaesthetists to follow this advice. ${ }^{2,9,10}$ In this larger study we sought to find out whether these differences persist.

${ }^{1}$ Department of Respiratory Medicine, Royal Bournemouth Hospital, Castle Lane East, Bournemouth BH7 7DW;

${ }^{2}$ Shackleton Department of Anaesthetics, Southampton General Hospital NHS Trust, Southampton SO16 6YD, UK

Correspondence to: Dr Dan Sado

E-mail: dan_sado@yahoo.com

\section{METHODS}

A six-question survey was hand-delivered to doctors from eight hospitals where the authors were working. They were asked whether, when dealing with adults, they would routinely give a local anaesthetic injection before insertion of IV cannulae of various sizes or ABG sampling. The study group was subdivided into medical doctors and surgical doctors. A further question was added to the questionnaire given to anaesthetists - would they give a local anaesthetic before arterial line insertion? We felt this was more relevant since patients treated by anaesthetists are more likely to have an arterial line inserted than to have repeated ABG sampling. We asked anaesthetists of all grades to fill in the questionnaire, since most senior and junior doctors in this specialty will regularly be doing intravenous cannulations and arterial punctures. In the physician and surgeon groups we included only junior doctors, since they are the ones who do most of these procedures on hospital wards. The data were analysed by use of Microsoft Excel 2000, with subgroup analysis by chi-square testing. $P<0.05$ was taken as significant.

\section{RESULTS}

The questionnaire was delivered to 178 doctors - 77 in anaesthesia, 51 in surgery and 50 in medicine - all of whom responded. All the consultants (32), all the staff grades (3) and most of the specialist registrars (32/45) were anaesthetists. Figure 1 summarizes the results. For ABG sampling and for insertion of all but the smallest IV cannula $(22 \mathrm{G})$, anaesthetists used local anaesthesia significantly more than the medical and surgical doctors $(P<0.01)$. For 


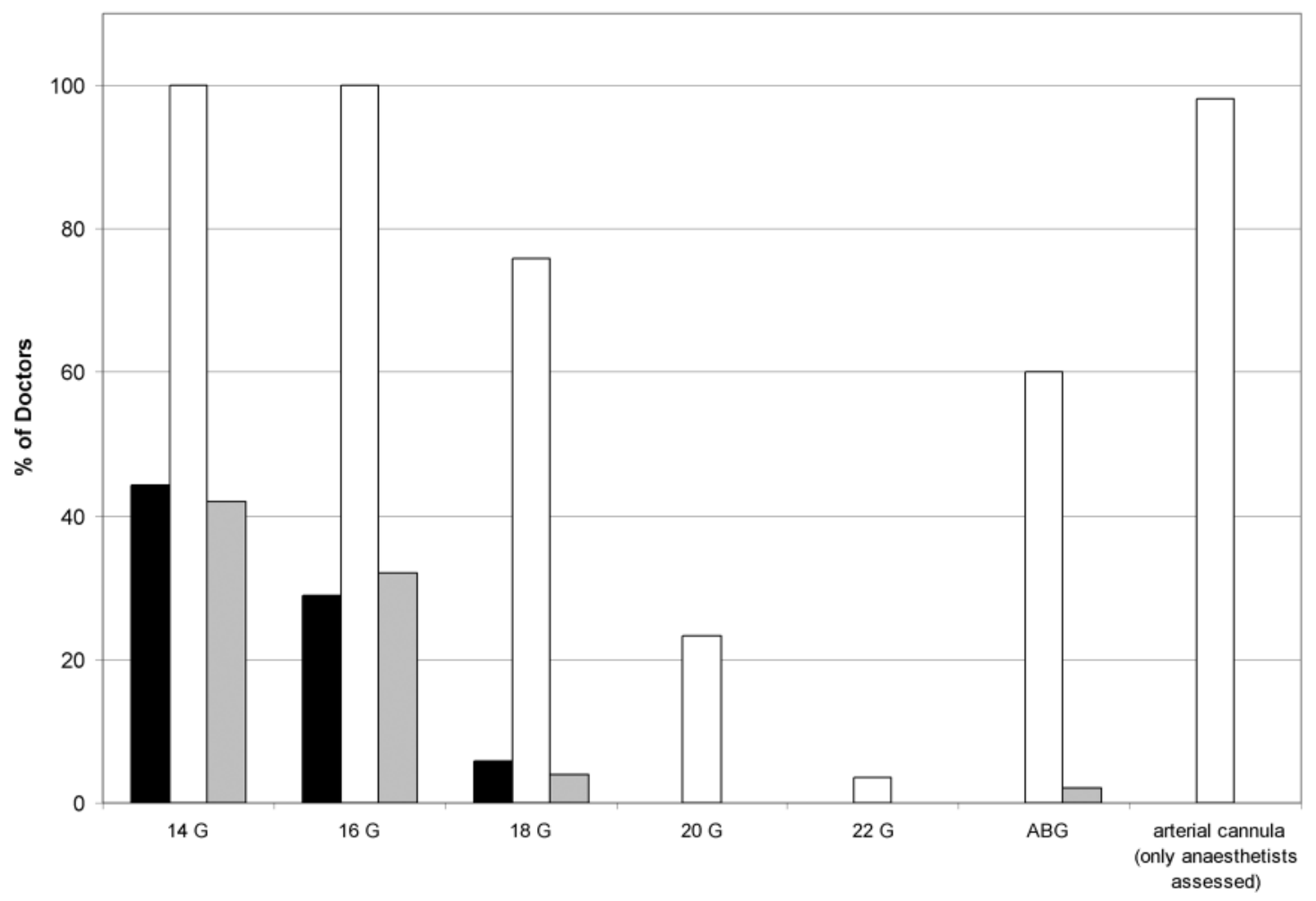

Figure 1 Percentages of doctors using local anaesthesia for venous cannulation, arterial blood gas sampling and arterial cannulation. - Physicians; $\square$ anaesthetists; surgeons

large-bore IV cannulae local anaesthesia was used by all the anaesthetists but less than half the others. For ABG sampling local anaesthesia was used by $60 \%$ of anaesthetists but only $2 \%$ of physicians and no surgeons; $98 \%$ of anaesthetists used local anaesthesia for arterial line insertion.

\section{DISCUSSION}

The surveys conducted 8-12 years ago ${ }^{2,9,10}$ indicated that anaesthetists were much more likely than non-anaesthetists to use local anaesthesia for these procedures; moreover, a large majority of junior doctors had never used it for either venous cannulation or arterial puncture. The present results, though confined to routine use, indicate that little has changed.

A weakness of our comparison of anaesthetists and nonanaesthetists is their unequal seniority - a necessary consequence of the study design. However, two observations make us think that the observed differences were attributable to specialty rather than seniority. First, of the few nonanaesthetic specialist registrars we surveyed, none replied that they would use local anaesthesia for either procedure. Second, most of the anaesthetics senor house officers said they used local anaesthesia for both. Another reason for the lower use by non-anaesthetists might be lack of training. ${ }^{10}$ Unlike their colleagues in other specialties, junior doctors in anaesthetics commonly receive instruction from senior staff, in the anaesthetic room, on how to carry out procedures. Our survey did not inquire about training. The advent of clinical skills rooms in most UK medical schools should allow cannulation to be taught on manikins, and we hope that future training will include the need for local anaesthesia.

What other factors could have contributed to the differences? One is the question of availability and time. In the anaesthetic room the drug is often drawn up by the technician and so is ready for the anaesthetist to use. By contrast, on the medical and surgical wards that we assessed, the lidocaine was kept in a locked drug cabinet and the doctor had to find a nurse with the keys. In emergency departments, our personal experience is that lidocaine is not kept under lock and key. When we asked ward nurses why lidocaine was locked up they offered two answers. First, it is a drug, and drugs must be stored securely. Second, the preparation from one of the manufacturers, in a plastic container, looks exactly like that for the saline/ water-for-injection cannula flushes and the two could be confused, with potentially disastrous results. This second objection could be dealt with by a change in packaging. A further issue highlighted by some doctors was the likelihood that local anaesthetic injection would make the procedure more difficult by obscuring the anatomy. This notion, however, is contradicted by previous studies, one of which concerned IV cannulation by casualty officers. ${ }^{11}$ Yet another concern was that the pain of two needles was worse than 
the pain of one. Again, the research evidence offers no support for this idea. The pain of local anaesthetic injection is only $1-2 / 10$ in severity, and thereafter the procedure of venous cannulation or ABG sampling should be virtually painless. ${ }^{1,6,7}$ If the pain of initial injection is deemed an issue, various ways to lessen it have been suggested including buffering with sodium bicarbonate to reduce acidity, ${ }^{12}$ warming of the solution, ${ }^{13}$ and injection via a $27 \mathrm{G}$ needle of the sort used for subcutaneous insulin.

In conclusion, this survey indicates that anaesthetists are still far more likely than doctors in medicine and surgery to use local anaesthesia for IV cannulation and arterial puncture. Junior doctors are giving their patients more pain than is necessary. Many of the justifications offered for non-use of local anaesthesia are untrue.

\section{REFERENCES}

1 Harrison N, Langham BT, Bogod DG. Appropriate use of local anaesthetic for venous cannulation. Anaesthesia 1992;47:210-12

2 Lightowler JV, Elliott MW. Local anaesthetic infiltration prior to arterial puncture for blood gas analysis: a survey of current practice and a double blind placebo controlled trial. J R Coll Physicians Lond 1997;31:645-6
3 Van Der Berg AA, Abeysekera RM. Rationalising venous cannulation: Patient factors and lignocaine efficacy. Anaesthesia 1993;48:84

4 Harris T, Cameron PA, Ugoni A. The use of pre cannulation local anaesthetic and factors affecting pain perception in the emergency department setting. Emergency Med J 2001;18:175-7

5 Giner J, Casan P, Sanchis J. Sampling arterial blood with a fine needle. Chest 1997;111:1474

6 Giner J, Casan P, Belda J, Gonzalez M, Miralda RM, Sanchis J. Pain during arterial puncture. Chest 1996;110:1443

7 Langham BT, Harrison DA. Local anaesthetic: Does it really reduce the pain of insertion of all sizes of venous cannula. Anaesthesia 1992;47:890-1

8 Michael A, Andrew M. The application of EMLA and glyceryl trinitrate ointment prior to venepuncture. Anaesth Intens Care 1996; 24: $360-4$

9 Paton RH. Local anaesthesia and venous cannulation. Anaesthesia 1995; 50:1005-6

10 Yentis SM. Use of intravenous cannulae by junior hospital doctors. Postgrad Med J 1993;69:389-91

11 Holdgate A, Wong G. Does local anaesthetic affect the success rate of intra venous cannulation? Anaesth Intens Care 1999;27:257-9

12 Mader TJ, Playe SJ, Garb JL. Reducing the pain of local anaesthetic infiltration: Warming and buffering have a synergistic effect. Ann Emerg Med 1994;23:550-4

13 Ong EL, Lim NL, Koay CK. Towards a pain free venepuncture. Anaesthesia 2000;55:260-2 